\title{
Embryonic Stem-like Cells Derived from in vitro Produced Bovine Blastocysts
}

\author{
Erika Regina Leal de Freitas ${ }^{1}$, Bruno Valente Sanches $^{2}$, Maria Lúcia Gambarini ${ }^{2}$, Benedito \\ Dias Oliveira Filho ${ }^{2}$ and Lidia Andreu Guillo ${ }^{1 *}$ \\ ${ }^{1}$ Departamento de Bioquímica e Biologia Molecular; Instituto de Ciências Biológicas; Universidade Federal de \\ Goiás. ${ }^{2}$ Departamento de Produção Animal; Universidade Federal de Goiás; C.P.: 131; 74001-970; Goiânia - GO \\ - Brazil
}

\begin{abstract}
The aim of this work was to study the derivation of bovine embryonic stem-like (ES-like) cells from the inner cell mass (ICM) of in vitro produced blastocysts. The ICMs were mechanically isolated and six out of seventeen (35\%) ICMs could attach to a monolayer of murine embryonic fibroblasts (MEF).Ten days after, primary outgrowths were mechanically dissected into several small clumps and transferred to a new MEF layer. Cells were further propagated and passaged by physical dissociation over a 60 days period. The pluripotency of the bovine ES-like cells was confirmed by RT-PCR of Oct-4 and STAT-3 gene markers. The colonies were weakly stained for alkaline phosphatase and the mesoderm and endoderm differentiation gene markers such as GATA-4 and Flk-1, respectively, were not expressed. Embryoid bodies were spontaneously formed at the seventh passage. Results showed that bovine ES-like cells could be obtained and passaged by mechanical procedures from the fresh in vitro produced blastocysts.
\end{abstract}

Key words: Bovine blastocysts, ICM isolation, Embryonic stem cells, Gene markers

\section{INTRODUCTION}

Embryonic stem (ES) cells were first isolated from the inner cell mass (ICM) of mouse blastocysts (Evans and Kauffmann, 1981) and since then the derivation of ES cells from many species, including humans have been reported. Several techniques for obtaining the ICM as well as for propagating the ICM-derived embryonic stem cells have been described. For the isolation of ICM; the most popular is immunosurgery where blastocyst's outer trophectodermal cells are eliminated by an antibody-complement reaction. Although very efficient to derivate the human embryonic stem cells (Heins et al., 2004; Kim et al., 2005), the method is dependent on the availability of the species-specific antibody/ antiserum. For example, only recently the antiserum against rabbit embryos was successfully used to isolate the ICM and the putative ES cells (Chiang et al., 2007). However, there is no commercially available antibody/antiserum against bovine embryos.

Trypsin treatment of blastocysts to remove the trophectoderm cells was also used to isolate the inner cell masses in miniature pigs, buffalo and goat (Li et al., 2004; Verma et al., 2007; Pawar et al., 2009). Similarly, the initial outgrowth and the ES colonies can be propagated by the treatment

*Author for correspondence: lidia.guillo@gmail.com 
with collagenase, trypsin or dispase (Oh et al., 2005; Suemori et al., 2006; Wang et al., 2007), although in a recently isolated cat ES-like cells, propagation by trypsin dissociation resulted in cell differentiation ( $\mathrm{Yu}$ et al., 2008). The enzymatic digestion of zona-free blastocysts was reported in cattle (Yadav et al., 2005), but trypsin treatment for the subsequent passage of primary colony has not been adopted by many researchers, since the most bovine ICM-derived ES cells reported to date are sensitive to enzymes.

The mechanical isolation is another important technique to obtain the ICM and propagate the colonies. Although considered a laborious technique, it has been re-evaluated for the isolation of human ES cells for further therapeutic purposes, where the use of animal derived biological components is no longer acceptable (Meng et al., 2010).

The physical isolation of bovine ICM is a widely disseminate technique to obtain the ES cultures. Usually, a micromanipulation chamber over the stage of an inverted microscope are used, equipment not frequently disposable to cell culturists that aims to isolate the bovine ES. Furthermore, until now, no authentic bovine ES cells have been obtained despite the use of these more sophisticated techniques (Talbot and Blombergle, 2008; Cao et al., 2009).

The aim of this study was to establish and characterize the embryonic stem cells from fresh in vitro produced bovine blastocysts (IVP), using the mechanical isolation of ICM and mechanical propagation of the colonies.

\section{MATERIALS AND METHODS}

\section{Embryos}

A total of 31 bovine in vitro produced (IVP) blastocysts (day 7) were kindly donated from In Vitro Brazil Ltda. Of these, 17 were expanded and 14 were hatched blastocysts (Fig. 1A). All the procedures of the embryo production were performed at In Vitro Brazil Ltda, enterprise specialized in IVP. Blastocysts were transferred to phosphate buffered saline (PBS; Gibco-Invitrogen, USA) supplemented with $10 \%$ fetal bovine serum (FBS; Cultilab, Brazil) and immediately processed to isolate the ICM.

\section{Isolation and culture of murine embryonic fibroblasts}

The isolation and expansion of murine embryonic fibroblasts (MEF) was based on the published standard protocols (Bryja et al., 2006). MEF were derived from the mice's embryos. For their isolation, females were sacrificed between the $13^{\text {th }}$ and $14^{\text {th }}$ day of conception. Fetuses were isolated and placed in PBS, and the heads and limbs were removed. The carcasses were washed with PBS, dissociated in $0.25 \%$ trypsin/EDTA (Cultilab, Brazil), and placed in the culture flasks containing DMEM medium (Gibco-Invitrogen, USA) supplemented with 10\% FBS (Cultilab, Brazil), penicillin $(100 \mathrm{UI} / \mathrm{ml}) /$ streptomycin $(100 \mu \mathrm{g} / \mathrm{ml})$ (Gibco-Invitrogen, USA) and kept at $37^{\circ} \mathrm{C}$ under $5 \% \mathrm{CO}_{2}$. After a few days, fibroblasts became visible and were left to grow near the confluence, when they were ready to be frozen and stored for later use. A high viability was obtained by freezing the fibroblasts directly in a solution containing DMEM (Gibco-Invitrogen, USA), 20\% FBS (Cultilab, Brazil) and 10\% dimethyl sulfoxide (DMSO, Invitrogen, USA). MEF were cultivated in culture flasks previously coated with $0.1 \%$ gelatin (Sigma-Aldrich Chemical Co., USA) containing DMEM (Gibco- Invitrogen, USA) supplemented with 10\% FBS (Cultilab, Brazil), 2mM L-glutamine (Gibco-Invitrogen, USA) and penicillin $(100 \mathrm{UI} / \mathrm{ml}) / \mathrm{streptomycin}(100 \mu \mathrm{g} / \mathrm{ml})$ (Gibco-Invitrogen, USA). Subcultures were routinely performed every two days using $0.05 \%$ trypsin/EDTA (Gibco-Invitrogen, USA). The day before bovine ES-like cells seeding, MEF were mitotically inactivated with $10 \mu \mathrm{g} / \mathrm{ml}$ mitomycin C (Sigma-Aldrich Chemical Co., USA) for $3 \mathrm{~h}$ at $37^{\circ} \mathrm{C}$ and $5 \% \mathrm{CO}_{2}$.

\section{Mechanical isolation of the ICM and culture of bovine embryonic stem-like cells}

The ICM was manually isolated using two syringe metal needles (18G - BD, USA) under a stereomicroscope (Nikon-1500). The morphologically intact ICM (Fig. 1B) were transferred to a feeder layer of mitotically inactivated MEF in minimum essential medium $\alpha$ $(\alpha$-MEM; Invitrogen, USA), supplemented with $15 \%$ FBS (Hyclone; Logan, UT), $0.1 \mathrm{mM} 2-$ mercaptoethanol (Invitrogen, USA), human leukemia inhibitory factor (LIF) at $10 \mathrm{ng} / \mathrm{ml}$ 
(Esgro, USA), penicillin (100 IU/ml), and streptomycin $(50 \mu \mathrm{g} / \mathrm{ml})$ and maintained at $37^{\circ} \mathrm{C}$ under $5 \% \mathrm{CO}_{2}$. Approximately 2-4 days later, the primary outgrowth of the ICM-derived cells could be seen. After 10 days of primary culture, the colony was first dissected into small pieces with a housekeeping knife, disaggregated by pipetting up and down and then transfer to a fresh feeder layer. The ES-like cell colonies were further propagated as described for the primary colony until passage 6. For passages, colonies with signs of differentiation (with a not defined demarcation boundary) were discarded.

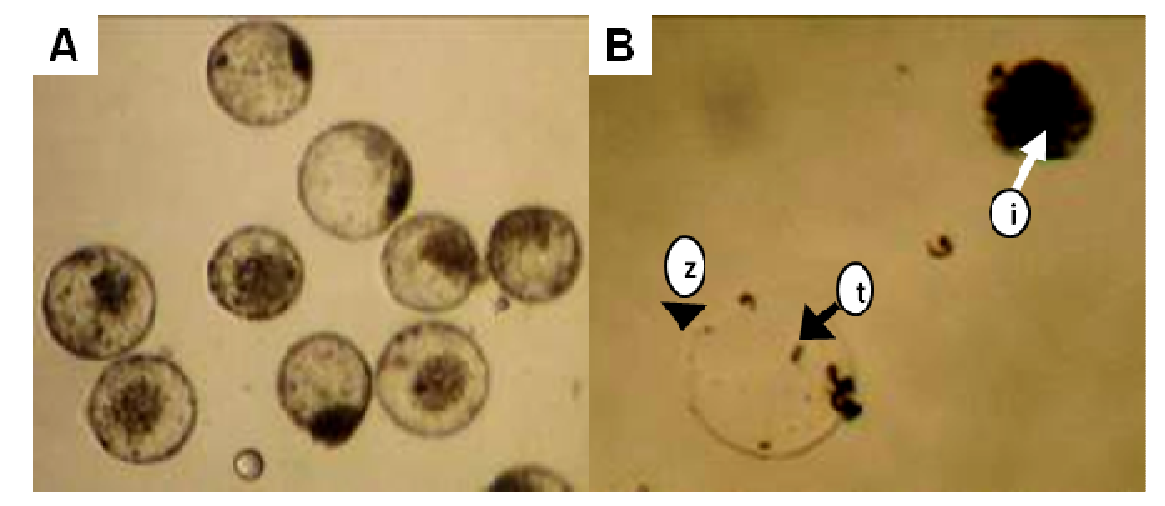

Figure 1 - Mechanically isolated bovine ICM. (A) Expanded and hatched blastocysts. (B) ICM (i) separated from the zona pellucida $(\mathbf{z})$ and trophoblast cells $(\mathbf{t})$.

\section{Alkaline phosphatase staining}

An assay was performed in order to determine the alkaline phosphatase (AP) activity in the bovine ES-like cells. A solution of 5-bromo-4-chloro-3indol phosphate/nitro blue tetrazolium (BCIP/ NBT) (Roche) was prepared, according to manufacturer's specifications. The analysis was performed on the cells previously fixed with $4 \%$ paraformaldehyde for $15 \mathrm{~min}$ at room temperature. After rinsing with PBS, the BCIP/NBT solution was added and fixed cells were incubated for 30 min in a dark environment. Cells with alkaline phosphatase activity showed a dark blue coloration.

\section{Reverse transcription-polymerase reaction (RT-PCR) analysis}

The characterization of the undifferentiated state of the bovine ES-like cells was performed by RTPCR. Total RNA was extracted from the bovine ES-like cells using Trizol (Invitrogen, USA), and quantified using a fluorimeter (Qubit $^{\mathrm{TM}}$, Invitrogen, USA). Two micrograms of the RNA samples were DNase-treated (Invitrogen, USA) for 15 minutes at room temperature. The samples were equally fractionated and one microgram of DNase-treated RNA was reverse-transcribed using Thermo Script RT-PCR ${ }^{\mathrm{TM}}$ kit (Invitrogen, USA), according to manufacturer's specifications. RTnegative controls (not reverse-transcribed) were also included. PCR reaction mixture was composed of $0.25 \mu \mathrm{M}$ of each primer (Table 1), $2 \mathrm{mM} \mathrm{MgCl} 2,0.1 \mathrm{mM}$ of each dNTPs, $2.5 \mathrm{U} \mathrm{Taq}$ Polymerase in $1 \mathrm{X}$ PCR buffer (Invitrogen, USA) and $2 \mu \mathrm{L}$ cDNA in a total volume of $25 \mu \mathrm{L}$. The following cycle conditions were applied for STAT-3, GATA-4, Flk-1 primers: an initial $5 \mathrm{~min}$ denaturing at $94^{\circ} \mathrm{C}$, followed by 40 cycles of $15 \mathrm{~s}$ at $94^{\circ} \mathrm{C}, 30 \mathrm{~s}$ at $55^{\circ} \mathrm{C}, 1 \mathrm{~min}$ at $72^{\circ} \mathrm{C}$ and final extension of $10 \mathrm{~min}$ at $72^{\circ} \mathrm{C}$ (Kurosaka et al., 2004). Cycle conditions for Oct-4 primer were 5 min at $94^{\circ} \mathrm{C}$, followed by 40 cycles of $15 \mathrm{~s}$ at $94^{\circ} \mathrm{C}, 30 \mathrm{~s}$ at $57^{\circ} \mathrm{C}, 45 \mathrm{~s}$ at $72^{\circ} \mathrm{C}$ and final extension of $7 \mathrm{~min}$ at $72^{\circ} \mathrm{C}$ (Saito et al., 2002).

The amplified products: 314 bp (Oct-4), $531 \mathrm{bp}$ (STAT-3), 510 bp (GATA-4) and 197 bp (Flk-1) were analyzed by electrophoresis on $1.5 \%$ agarose gel containing ethidium bromide $(1 \mu \mathrm{g} / \mathrm{mL})$. As negative control, samples without cDNA were also used in the PCR reaction. 
Table 1 - Sequence of primers used in RT-PCR analysis.

\begin{tabular}{|c|c|c|c|}
\hline Gene & Primer sequence & Product (bp) & References \\
\hline Oct-4 & $\begin{array}{l}5^{\prime} \text { - GGTTCTCTTTGGAAAGGTGTTC-3, } \\
5^{\prime} \text { - ACACTCGGACCACGTCTTTC-3, }\end{array}$ & 314 & Kurosaka et al., 2004 \\
\hline STAT-3 & $\begin{array}{l}\text { 5'- TCTGGCTAGACAATATCATCGACCTTG-3, } \\
\text { 5'-TTATTTCCAAACTGCATCAATGAATCT-3, }\end{array}$ & 531 & Saito et al., 2002 \\
\hline GATA-4 & $\begin{array}{l}\text { 5'- CTCTGGAGGCGAGATGGGACGGG-3' }{ }^{\text {a }} \\
\text { 5'-GAGCGGTCATGTAGAGGCCGGCAGGCATT-3 }{ }^{\text {, }}\end{array}$ & 510 & Saito et al., 2002 \\
\hline Flk-1 & $\begin{array}{l}\text { 5'-CTGCCTACCTCACCTGTTTCCTGTATGG-3, } \\
\text { 5'-GGATATCTTGAAATGTTTTTACACTCAC-3, }\end{array}$ & 197 & Saito et al., 2002 \\
\hline
\end{tabular}

${ }^{\mathrm{a}}$ Forward primer; ${ }^{\mathrm{b}}$ Reverse primer.

\section{RESULTS AND DISCUSSION}

\section{Isolating of the ICM and bovine ES-like cells}

Within the initial $48 \mathrm{~h}$, none of the ICMs from the hatched blastocysts were able to adhere to MEF layer. The reason for this was not known. Among the expanded blastocysts, six became attached to MEF layer (Fig. 2B). The ICMs continued to grow (Fig 2C) culminating with the formation of a button in the middle of a large colony (primary colony, Fig. 2D). Ten days after, the primary colony was mechanically dissected as described in Material and Methods and further propagated, originating the putative ES-like cells (Fig. 2E-F). These cells grew and formed flat colonies with well defined boundary (Fig. 2H-J).

These cells were classified as embryonic stem cells according to their morphology, namely, a small ratio cytoplasm/nucleus, a nucleus with multiple nucleoli, and cytoplasmic vesicles (Stice et al., 1996; Cibelli et al., 1998; Mitalipova et al., 2001). One ES-like line with these characteristics were established and maintained by six passages for two months. After this period, the spontaneous differentiation occurred (Fig. 2K) and culminated with the formation of embryoid bodies (EB) (Fig. 2L). This differentiation could be due to the decrease/absence of expression of auto-renewal factors after the first passages, thus becoming difficult to attain a permanent cellular line (Gjorret and Maddox-Hyttel, 2005).

\section{Expression of pluripotency markers by the bovine embryonic stem like-cells}

In an attempt to characterize these cells, the expression of markers normally associated with the undifferentiated pluripotent state was done. Alkaline phosphatase activity has been used to identify the pluripotent cells in the cultures derived from livestock species (Talbot et al., 2000; Li et al., 2003). In the present study, the colonies at sixth passage did not stain or stain weakly for the alkaline phosphatase (Fig. 3). Conflicting results have been reported in relation to AP staining in the bovine embryonic stem cells. Cao et al. (2009) detected a strong AP activity in both, the primary bovine ES-like colony and trophoctoderm cells.

Yadav et al. (2005) observed a weak or absent AP activity in the bovine embryonic ES-like cells. Therefore, AP activity might not be a good pluripotency marker for the bovine embryonic stem cells.

The level of Oct- 4 and STAT- 3 gene expression was further studied. Oct-4 is a critical transcription factor frequently used as marker for the undifferentiated cells. High expression levels have been found in human ES cells (Reubinoff et al., 2000), mouse ES cells (Berril et al., 2004), equine ES cells (Saito et al., 2002) and bovine ES cells (Saito et al., 2003).

Kurosaka et al. (2004) showed that the Oct-4 mRNA expression pattern was restricted to ICM cells in the bovine blastocysts. Therefore, Oct- 4 transcription factor was a suitable marker for the identification of pluripotent cells in cattle. STAT-3 was another key regulator for self-renewal of ES cells in mouse (Matsuda et al., 1999) and it was also expressed in the bovine ES cells (Saito et al., 2003). The fragments of 314 bp (Oct-4) and 531 bp (STAT-3) were amplified, thus indicating that the colonies were formed by the cells in undifferentiated state (Figure 3 ).

Some mesoderm and endoderm gene markers as GATA-4 and Flk-1 respectively, were also assayed by RT-PCR. They have been used to monitor the in vitro progression of $\mathrm{ES}$ cell cultures to $\mathrm{EB}$ formation (Koike et al., 2007). These genes were not expressed in the present ES-like cells grown until the sixth passage, confirming the undifferentiated state of these cells (Fig. 3). 


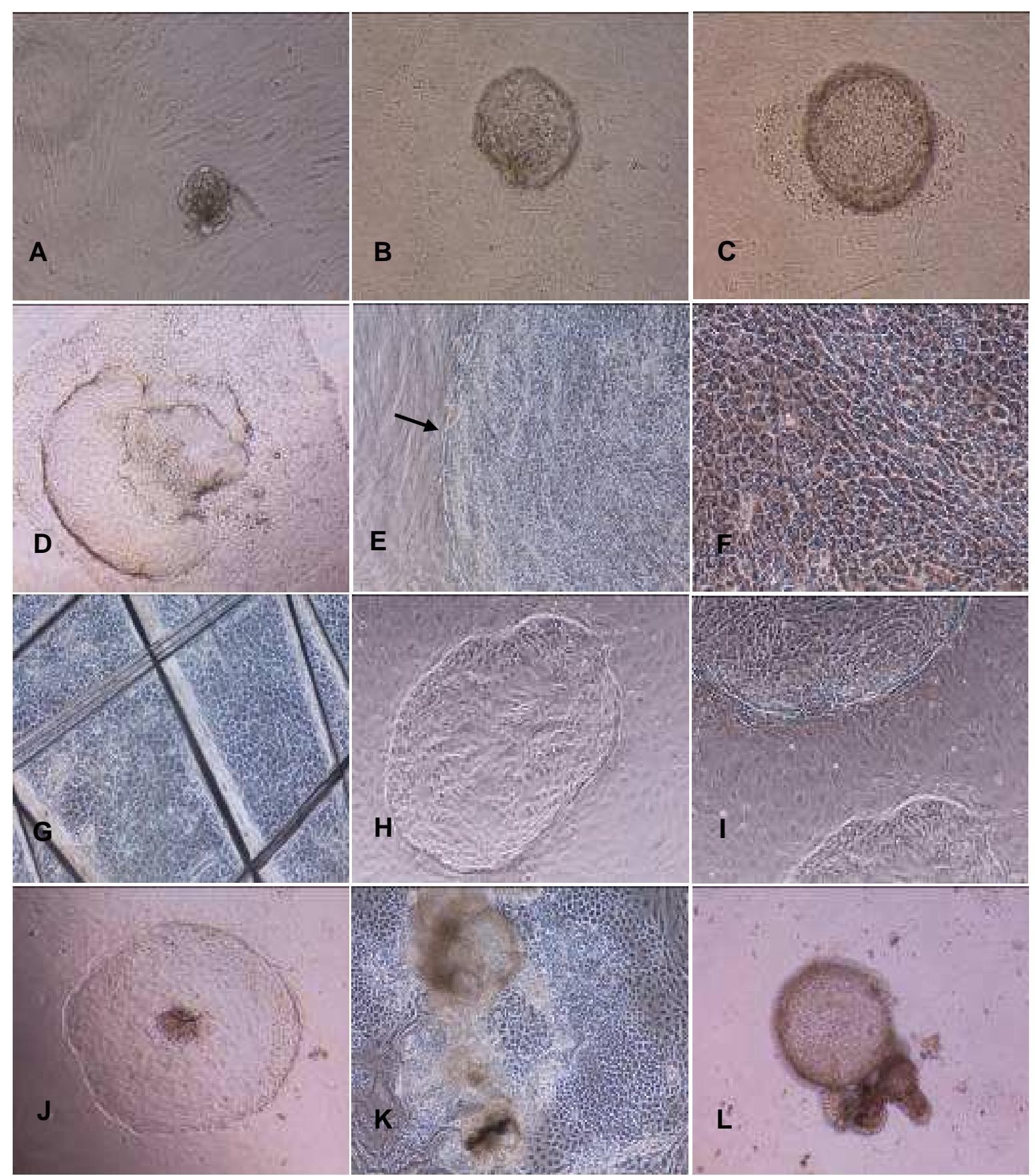

Figure 2 - Phase contrast micrographs of bovine ES-like cells and their differentiated derivatives. (A) A fresh isolated ICM over a MEF layer. (B) ICM expansion after attachment to MEF layer. (C) ICM outgrowth after $48 \mathrm{~h}$ isolation. Note that trophoblast cells were not seen. (D) Formation of a button in the middle of a large colony (primary colony). (E) Bovine ES-like cell colony after the first passage. Note the defined demarcation boundary of colony (arrow). (F) A higher magnification at the middle of the colony shown in (E). (G) Mechanical cut of bovine ES-like colony. (H-J) Flat colonies of bovine ES-like cells at different passages. (K) Bovine ES-like colony undergoing spontaneous differentiation. (L) Embryoid body (EB) from differentiated bovine ES-like cells. Magnification: x200 (A-C, F) and x100 (D-E, G-L). 

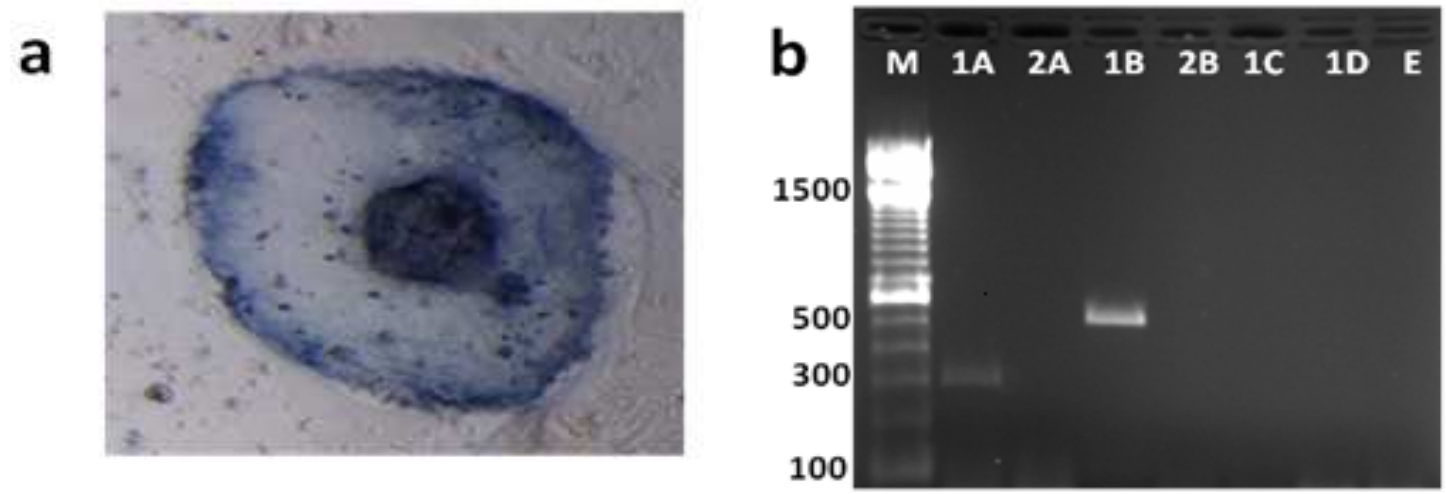

Figure 3 - Analysis of the undifferentiated state of the bovine embryonic stem-like cells. (a) Alkaline phosphatase staining of a representative colony at sixth passage. (b) RT-PCR analysis of genes associated with pluripotency of bovine ES-like cells. PCR product of DNase-treated RNA. Lane 1: reverse-transcribed. Lane 2: without reverse-transcriptase to rule out genomic DNA contamination. (A) Oct-4 (314 bp), (B) STAT-3 (531 bp), (C) GATA-4 (510 bp), (D) Flk-1(197 bp) and (E) Sample without cDNA (negative control of the PCR reaction). (M) $100 \mathrm{bp}$ DNA ladder.

Indeed, validated ES cell lines have yet to be established in cattle (Keefer et al., 2007; Talbot et al., 2008). Up till now, regardless of the technique, only short-lived cultures have been described. The mechanical propagation of bovine ES-like cells was reported not to exceed seven passages in culture (Yadav et al., 2005). In combination procedures (mechanical dissociation for only the first three passages, followed by subsequent passages with trypsin), bovine ES-like cell colonies are maintained up to 10 passages (Gong et al., 2010).

The physical isolation procedures of human ES cells have regained attention in last years since the possibilities of their use in cell therapy are being confirmed (Meng et al., 2010). This study has demonstrated that the mechanical isolation of ICMs and mechanical propagation of colonies could be an inexpensive alternative for obtaining the bovine ES-like cells. The maintenance of a bovine ES cell lineage seemed to depend less on the technical procedures than the knowledge of the mechanisms that promote or influence cell pluripotency. This is not an easy task, as recently reported by Cao et al. (2009), the pathways needed to maintain the undifferentiated state of bovine ES cells seem to be different from the already known pathways found in mice and humans.

In summary, we were able to isolate bovine ICMderived ES-like cells by mechanical procedures.
These cells had typical embryonic stem cell morphology and expressed gene ES cell markers as Oct-4 and STAT-3. Colonies at sixth passage have not expressed the mesoderm and endoderm gene markers GATA-4 and Flk-1 respectively. Embryoid bodies were spontaneously formed at the seventh passage. By using these mechanical procedures, future studies should be carried to optimize the culture conditions (e.g. medium, supplements and growth factors) to extend the time in culture and the number of times the culture could be passaged.

\section{ACKNOWLEDGMENTS}

This work was financially supported by protocol $\mathrm{n}^{\mathrm{o}} 552593 / 2005-2$ from Ministry of Health and from National Research Council (CNPq) of Brazil. The authors wish to thank to Dr. Mário Approbato (Laboratório de Reprodução Humana/UFG) for assistance on initial experimental delineation of embryo's obtainment. We also thank to Jane Porfírio and Rita de Cássia Pereira da Costa e Silva for valuable collaboration in initial experiments. Authors thank to In Vitro Brasil Ltda for donation of embryos. 


\section{REFERENCES}

Berrill, A., Tan, H. L., Wuang, S. C., Fong, W. J., Choo, A. B. and Oh, S. K. (2004), Assessment of stem cell markers during long-term culture of mouse embryonic stem cells. Cytotechnology, 44, 77-91.

Bryja, V., Bonilla, S. and Arenas, E. (2006), Derivation of mouse embryonic stem cells. Nat. Protoc., 1, 2082-2087.

Cao, S., Wang, F., Chen, Z., Liu, Z., Mei, C., Wu, H., Huang, J., Li, C., Zhou, L. and Liu, L. (2009), Isolation and culture of primary bovine embryonic stem cell colonies by a novel method. J. Exp. Zool. Part. A. Ecol. Genet. Physiol., 311, 368-376.

Chiang, S. K., Chang, H. H., Ou, Y. W., Intawicha, P., Cheng, S. P., Chen, L. R., Lee, K. H., Giles, J. and Ju, J. C. (2007), Successful induction of antisera against rabbit embryos for isolation of the ICM and putative embryonic stem cells. Reprod. Domest. Anim., 43, 181-188.

Cibelli, J. B., Stice, S. L., Golueke, P. J., Kane, J. J., Jerry, J., Blackwell, C., Ponce de León, F. A. and Robl, J. M. (1998), Transgenic bovine chimeric offspring produced from somatic cell-derived stemlike cells. Nat. Biotechnol., 16, 642-646.

Evans, M. J. and Kaufman, M. H. (1981), Establishment in culture of pluripotential cells from mouse embryos. Nature, 292, 154-156.

Gjørret, J. O. and Maddox-Hyttel P. (2005), Attempts towards derivation and establishment of bovine embryonic stem cell-like cultures. Reprod. Fertil. Dev., 17, 113-124.

Gong, G., Roach, M. L., Jiang, L., Yang, X. and Tian, X. C. (2010), Culture conditions and enzymatic passaging of bovine ESC-like cells. Cell Reprogram., 12, 151-160.

Heins, N., Englund, M. C., Sjöblom, C., Dahl, U., Tonning, A., Bergh, C., Lindahl, A., Hanson, C. and Semb, H. (2004), Derivation, characterization, and differentiation of human embryonic stem cells. Stem Cells, 22, 367-376.

Keefer, C. L., Pant, D., Blomberg, L. and Talbot, N. C. (2007), Challenges and prospects for the establishment of embryonic stem cell lines of domesticated ungulates. Anim. Reprod. Sci., 98, 147168.

Kim, H. S., Oh, S. K., Park, Y. B., Ahn, H. J., Sung, K. C., Kang, M. J., Lee, L. A., Suh, C. S., Kim, S. H., Kim, D. W. and Moon, S. Y. (2005), Methods for derivation of human embryonic stem cells. Stem Cells, 23, 1228-1233.

Koike, M., Sakaki, S., Amano, Y. and Kurosawa, H. (2007), Characterization of embryoid bodies of mouse embryonic stem cells formed under various culture conditions and estimation of differentiation status of such bodies. J. Biosci. Bioeng., 104, 294299.
Kurosaka, S., Eckardt, S. and McLaughlin, K. J. (2004), Pluripotent lineage definition in bovine embryos by Oct4 transcript localization. Biol. Reprod., 71, 15781582.

Li, M., Zhang, D., Hou, Y., Jiao, L., Zheng, X. and Wang, W. H. (2003), Isolation and culture of embryonic stem cells from porcine blastocysts. Mol. Reprod. Dev., 65, 429-434.

Li, M., Ma, W., Hou, Y., Sun, X. F., Sun, Q. Y. and Wang, W. H. (2004), Improved isolation and culture of embryonic stem cells from Chinese miniature pig. J. Reprod. Dev., 50, 237-244.

Matsuda, T., Nakamura, T., Nakao, K., Arai, T., Katsuki, M., Heike, T. and Yokota, T. (1999), STAT3 activation is sufficient to maintain an undifferentiated state of mouse embryonic stem cells. EMBO J., 18, 4261-4269.

Meng, G., Liu, S., Li, X., Krawetz, R. and Rancourt, D. E. (2010), Derivation of human embryonic stem cell lines after blastocyst microsurgery. Biochem. Cell Biol., 88, 479-490.

Mitalipova, M., Beyhan, Z. and First, N. L. (2001), Pluripotency of bovine embryonic cell line derived from precompacting embryos. Cloning, 3, 59-67.

Oh, S. K., Kim, H. S., Park, Y. B., Seol, H. W., Kim, Y. Y., Cho, M. S., Ku, S. Y., Choi, Y. M., Kim, D. W. and Moon, S. Y. (2005), Methods for expansion of human embryonic stem cells. Stem Cells, 23, 605609.

Pawar, S. S., Malakar, D., De, A. K. and Akshey, Y. S. (2009), Stem cell-like outgrowths from in vitro fertilized goat blastocysts. Indian. J. Exp. Biol., 47, 635-642.

Reubinoff, B. E., Pera, M. F., Fong, C. Y., Trounson, A. and Bongso, A. (2000), Embryonic stem cell lines from human blastocysts: somatic differentiation in vitro. Nat. Biotechnol., 18, 399-404.

Saito, S., Ugai, H., Sawai, K., Yamamoto, Y., Minamihashi, A., Kurosaka, K., Kobayashi, Y., Murata, T., Obata, Y. and Yokoyama, K. (2002), Isolation of embryonic stem-like cells from equine blastocysts and their differentiation in vitro. FEBS Lett., 531, 389-396.

Saito, S., Sawai, K., Ugai, H., Moriyasu, S., Minamihashi, A., Yamamoto, Y., Hirayama, H., Kageyama, S., Pan, J., Murata, T., Kobayashi, Y., Obata, Y. and Yokoyama, K. K. (2003), Generation of cloned calves and transgenic chimeric embryos from bovine embryonic stem-like cells. Biochem. Biophys. Res. Commun., 309, 104-113.

Stice, S. L., Strelchenko, N. S., Keefer, C. L. and Matthews, L. (1996), Pluripotent bovine embryonic cell lines direct embryonic development following nuclear transfer. Biol. Reprod., 54, 100-110. 
Suemori, H., Yasuchika, K., Hasegawa, K., Fujioka, T., Tsuneyoshi, N. and Nakatsuji, N. (2006), Efficient establishment of human embryonic stem cell lines and long-term maintenance with stable karyotype by enzymatic bulk passage. Biochem. Biophys. Res. Commun., 345, 926-932.

Talbot, N. C., Caperna, T. J., Edwards, J. L., Garrett, W., Wells, K. D. and Ealy, A. D. (2000), Bovine blastocyst-derived trophectoderm and endoderm cell cultures: interferon tau and transferrin expression as respective in vitro markers. Biol. Reprod., 62, 235247.

Talbot, N. C. and Blombergle A. (2008), The pursuit of ES cell lines of domesticated ungulates. Stem Cell Rev., 4, 235-254.

Verma, V., Gautam, S. K., Singh, B., Manik, R. S., Palta, P., Singla, S. K., Goswami, S. L. and Chauhan, M. S. (2007), Isolation and characterization of embryonic stem cell-like cells from in vitro-produced buffalo (Bubalus bubalis) embryos. Mol. Reprod. Dev., 74, 520-529.
Wang, S., Tang, X., Niu, Y., Chen, H., Li, B., Li, T., Zhang, X., Hu, Z., Zhou, Q. and Ji, W. (2007), Generation and characterization of rabbit embryonic stem cells. Stem Cells, 25, 481-489.

Yadav, P. S., Kues, W. A., Herrmann, D., Carnwath, J.W. and Niemann, H. (2005), Bovine ICM derived cells express the Oct4 ortholog. Mol. Reprod. Dev., 72, 182-190.

Yu, X., Jin, G., Yin, X., Cho, S., Jeon, J., Lee, S. and Kong, I. (2008), Isolation and characterization of embryonic stem-like cells derived from in vivoproduced cat blastocysts. Mol. Reprod. Dev., 75, 1426-1432.

Received: January 08, 2010; Revised: July 29, 2010; Accepted: March 15, 2011. 